\title{
Examining Dark Triad traits in relation to mental toughness and physical activity in young adults
}

This article was published in the following Dove Press journal:

Neuropsychiatric Disease and Treatment

27 January 2016

Number of times this article has been viewed

\author{
Sarah Sabouri' \\ Markus Gerber ${ }^{2}$ \\ Dena Sadeghi Bahmani ${ }^{3}$ \\ Sakari Lemola ${ }^{4}$ \\ Peter J Clough ${ }^{5}$ \\ Nadeem Kalak ${ }^{3}$ \\ Mahin Shamsi' \\ Edith Holsboer-Trachsler ${ }^{3}$ \\ Serge Brand ${ }^{2,3}$ \\ 'Faculty of Educational Sciences \\ and Psychology, AllamehTabataba'i \\ University, Tehran, Iran; ${ }^{2}$ Department \\ of Sport, Exercise and Health, Sport \\ Science Section, University of Basel, \\ ${ }^{3}$ Center for Affective, Stress and \\ Sleep Disorders, Psychiatric Clinics \\ of the University of Basel, ${ }^{4}$ Faculty \\ of Psychology, University of Basel, \\ Basel, Switzerland; ${ }^{5}$ Department of \\ Psychology, Manchester Metropolitan \\ University, Manchester, UK
}

Correspondence: Serge Brand Center for Affective, Stress and Sleep Disorders, Psychiatric Clinics of the University of Basel, Wilhelm Klein-Strasse 27, 4012 Basel, Switzerland

$\mathrm{Tel}+41613255114$

Fax +4I 6I 3255553

Email serge.brand@upkbs.ch
Objective: The Dark Triad (DT) describes a set of three closely related personality traits: Machiavellianism, narcissism, and psychopathy. Mental toughness (MT) refers to a psychological construct combining confidence, commitment, control, and challenge. High MT is related to greater physical activity (PA) and, relative to men, women have lower MT scores. The aims of the present study were 1) to investigate the association between DT, MT, and PA, and 2) to compare the DT, MT, and PA scores of men and women.

Methods: A total of 341 adults ( $M=29$ years; 51.6\% women; range: $18-37$ years) took part in the study. Participants completed a series of questionnaires assessing DT, MT, and PA.

Results: Machiavellianism, narcissism, and psychopathy were all significantly associated with higher MT scores ( $r s=0.45,0.50$, and 0.20 , respectively). DT traits and MT were associated with more vigorous PA. Compared to men, women participants had lower scores for DT traits (overall score and psychopathy), while no differences were found for MT or PA in both sexes.

Conclusion: DT traits, high MT, and vigorous PA are interrelated. This pattern of results might explain why, for instance, successful professional athletes can at the same time be tough and ruthless.

Keywords: dark triad, mental toughness, physical activity, young adults, sex

\section{Introduction}

In 2002, Paulhus and Williams ${ }^{1}$ described the personality construct of the Dark Triad (DT), and since then, DT has been attracting increasing attention. ${ }^{2}$ DT consists of three dimensions: Machiavellianism (a manipulative, self-centered, immoral, and calculative attitude), narcissism (exaggerated self-love, dominant, self-aggrandized, egocentric), and psychopathy (lack of empathy, adventurousness, low anxiety, cold-blooded). Machiavellianism refers to a personality trait associated with taking advantage and being self-centered, immoral, and calculating, ${ }^{3}$ with frequent and extreme use of deception and manipulation. ${ }^{1,4}$ While Machiavellian individuals present themselves as charming and attractive personalities to impress their peers, ${ }^{4}$ they might remain hypocritical, superficial, and manipulative. ${ }^{3}$ Further, Machiavellianism did correlate with low agreeableness and conscientiousness in the "Big Five" model. ${ }^{1}$ A Machiavellianistic behavior is closely related to self-interest and personal gain. ${ }^{5}$ Narcissism is characterized by views of megalomania, exaggerated self-love, dominance, superiority, self-centeredness, self-aggrandizement, and egocentric attitude. ${ }^{1}$ In interpersonal relationships, narcissist people behave in an exploitative and egocentric way and try to take advantage of others to satisfy their admiration. ${ }^{6}$ Further, narcissism is negatively correlated with agreeableness and positively associated with the extraversion and openness to experience factors of the Big Five model. ${ }^{7}$ Lastly, psychopathy is associated with a tendency to be highly impulsive, adventurous, and cold-blooded and have little 
empathy and low anxiety. ${ }^{1}$ Similar to Machiavellianism and narcissism, psychopathy is associated with low empathy. ${ }^{8}$

Whereas the personality constructs of Machiavellianism, narcissism, and psychopathy had already been acknowledged within various areas of psychology and psychiatry, ${ }^{9,10}$ they were examined separately and in isolation from one another. ${ }^{11}$ Only with Paulhus and Williams ${ }^{1}$ did these three dimensions integrate into an overall construct. These authors also introduced the term "dark" to highlight the rather problematic and socially controversial set of mental attitudes and behaviors reflected in a shared use of antagonistic, dishonest, and egocentric interpersonal styles. ${ }^{1,9,10,12-14}$ Since then, research has identified associations between higher DT scores and increased sexual desire as well as rather impersonal, masochistic, and "harder" sexual behavior, ${ }^{15}$ lower intimacy in personal relationships, ${ }^{16}$ and poorer skills in managing and coping with money. ${ }^{17}$ Further, people scoring high on DT traits both report and display overt schadenfreude/gloating; ${ }^{18}$ view others' personalities as being less positive, desirable, or reliable; ${ }^{19}$ show and express more mating rivalry (backbiting, manipulation, lying); ${ }^{20}$ are more prone to aggressive, risky, illegal, racist, and impulsive behavior,;1,22 report being evening rather than morning or intermediate chronotypes; ${ }^{23}$ and are less intrinsically motivated to religious observance. ${ }^{24}$ Lastly, recent research has shown that men scoring high on DT traits spent more time in editing "selfies" posted on social network sites. ${ }^{25}$ On the other hand, women see "bad boys" (ie, men scoring high in DT traits) as physically and sexually attractive ${ }^{26}$ Additionally, and most importantly, people scoring high on DT traits seem to be more mentally tough. ${ }^{27}$

Mental toughness (MT) is a psychological construct related to positive stress management and a relatively new area of academic research. ${ }^{28}$ It involves a cognitive strength variable that is known to be associated with good performance both in elite sport ${ }^{29}$ and, more recently, in nonelite sport. ${ }^{30,31}$ Indeed, in previous studies, ${ }^{30-32}$ we employed the Mental Toughness Questionnaire-48 (MTQ48) ${ }^{33}$ and showed in several samples of adolescents and young adults, who were nonelite athletes, that 1) the construct of MT was associated with higher levels of physical activity (PA) among nonelite athletes, ${ }^{30-32}$ 2) MT was associated with greater stress resilience, ${ }^{30-32}$ 3) MT remained relatively stable over time, ${ }^{31}$ 4) MT was associated with higher PA levels, ${ }^{30,32} 5$ ) relative to men, women reported lower MT, and 6) higher MT was associated with both better subjective ${ }^{34}$ and objective sleep. ${ }^{35}$ These findings suggested, therefore, that MT is related to successful stress management, psychological well-being, superior sleep quality, and higher levels of PA. In conclusion, we note that MT is associated with a broad range of positive behaviors, including a straightforward, highly motivated strategy to achieve goals, along with a strong belief in oneself and one's own ability, and with greater PA.

Although in previous studies MT has been associated with success in sport ${ }^{36-39}$ and psychological well-being, some researchers have also identified potentially dysfunctional outcomes. ${ }^{37,40-44}$ (These dysfunctional outcomes are also called the "Dark side of Mental Toughness", though "dark" is misleading: here, "dark" is better translated as "costs," "disadvantages," "expenses," "exaggerations," or "downside.") More specifically, athletes with high MT seemed to be at a greater risk of ignoring medical advice and disregarding rehabilitation. For example, Coulter et al ${ }^{41}$ suggested that "mentally tough athletes may be overconfident or too committed to the pursuit of winning that they fail to recognize or accept medical advice about minor injuries, rendering them at a higher risk of major injury than players with less self-belief" ${ }^{43-45}$ From these studies we deduce that mentally tough athletes might be particularly committed to their aims while disregarding the costs and "side effects" as people scoring high in Machiavellianism often do. Accordingly, one aim of the present study was to explore the possible relation between MT and DT traits.

While most research related to the "dark side of mental toughness" has been conducted with elite athletes, to our knowledge, to date only one study has considered the relation between DT and MT in a nonelite sport population. Onley et $\mathrm{al}^{27}$ investigated the association between DT and MT among healthy adults and observed significant positive associations between MT and narcissism and negative associations between MT and psychopathy and Machiavellianism. Further, Onley et $\mathrm{al}^{27}$ claimed a common genetic basis to DT and MT. In the light of Onley et al's findings, we investigated whether the association between DT and MT could be replicated. Further, given the association between MT and PA, we asked whether DT might also be related to PA, and whether there are differences between sexes given that women typically have lower MT scores than men ${ }^{30,32}$ and lower PA levels. ${ }^{46}$

Accordingly, the following three hypotheses were formulated. First, following Onley et al, ${ }^{27}$ we anticipated that DT traits and MT would be correlated. Second, following Gerber et al, ${ }^{30,32}$ we expected that DT traits, MT and PA would be positively interrelated. Third, again following Gerber et al, ${ }^{30,32}$ we expected lower MT and PA scores among women than among men, and we expected that men would score higher on DT traits. ${ }^{21,47-49} \mathrm{We}$ believe that the present study has the 
potential to add to the current knowledge on DT and MT in an important way: it is possible that the pattern of results will help explain why, for example, athletes can be successful, ruthless, and selfish at the same time. Accordingly, the pattern of results might help clarify why nonathletes might also be mentally tough and concomitantly socially ruthless.

\section{Methods}

\section{Sample}

The sample consisted of 341 Iranian adults (age: $M=29.0$ years; $\mathrm{SD}=6.58$; range: $18-37$ years, $51.6 \%$ women; mean age of women participants: $\mathrm{M}=28.89, \mathrm{SD}=5.45$; mean age of men participants: $\mathrm{M}=29.23, \mathrm{SD}=7.45 ; t(339)=0.34, P>0.65$, $d=0.05$ ) who volunteered to take part in an online survey. All participants who joined the survey had a unique IP address. To recruit participants, the study was posted electronically on Facebook and other local social media networks (Cloob and Irexpert). Data were collected between December 2013 and July 2014.

\section{Procedures}

Data collection was done via the Internet, which is a both timely and reliable way to gather data (refer Brand et $\mathrm{al}^{50}$ for an overview). Commercially available software (Unipark ${ }^{\circledR}$; http://www.unipark.de) was used for data collection. The software is an easily applied tool for the creation of Internetbased studies. The software provider guarantees that all data are stored on a server that is not accessible to any third party. The user of the software receives the raw data related to the questionnaires but not to the IP address of the participants. Thus, both data security and participant anonymity are ensured. Moreover, to avoid repeat participation, the software is designed to block recruitment of subjects whose IP addresses have already been used. Participants were informed about the purpose of the study and about the voluntary basis of their participation. They were also assured of the confidentiality of their responses, and written informed consent was obtained on the first page of the questionnaire. Moreover, participants could discontinue or withdraw from the study without giving any further explanation. To improve compliance, participants could take part in a prize draw, although to do so they needed to provide an email address. Three iPod Shuffles ${ }^{\circledR}$ were raffled as prizes. Data were automatically gathered and afterward converted into an SPSS ${ }^{\circledR}$ file for further analysis.

The study was approved by the Review Board of the AllamehTabataba'i University, Faculty of Educational Sciences and Psychology, Tehran, Iran, and the entire study was conducted in accordance with the ethical standards laid down in the Declaration of Helsinki.

\section{Measures}

Participants completed a series of standardized questionnaires as follows:

\section{DT traits}

Machiavellianism was measured with the 20-item MACHIV. ${ }^{51}$ Participants were asked how much they agreed ( $1=$ strongly disagree; $5=$ strongly agree $)$ with statements such as: "Never tell anyone the real reason you did something unless it is useful to do so"; or "The best way to handle people is to tell them what they want to hear." Responses were averaged to create a Machiavellianism index, with higher mean scores reflecting stronger Machiavellianism (Cronbach's $\alpha=0.85$ ).

Narcissism was assessed with the 40-item Narcissistic Personality Inventory. ${ }^{52}$ For each item, participants were asked to rate how much they agreed $(1=$ strongly disagree; $5=$ strongly agree) with the statements that applied to them (eg, "Everybody likes to hear my stories"; and "I am an extraordinary person."). The items were summed to obtain a Narcissism index (Cronbach's $\alpha=0.92$ ). Higher scores reflect greater narcissism.

Subclinical psychopathy was assessed by the 40-item Self-Report Psychopathy Scale-III. ${ }^{53}$ Participants rated how much they agreed ( $1=$ strongly disagree; $5=$ strongly agree $)$ with statements such as "I almost never feel guilty" or "I think I could beat a lie detector". Responses across items were averaged to create an overall index of psychopathy (Cronbach's $\alpha=0.88$ ), with higher scores indicating greater psychopathy.

In addition to examining the DT traits separately, we also created a composite measure of the overall DT. As recommended by Jonason et al, ${ }^{54}$ we first standardized ( $z$-scored) overall scores for each measure, and then averaged all three scores to create a composite DT index. A principal component factor analysis showed that all three measures loaded well $(>0.52)$ on a single factor that accounted for $52.11 \%$ of the variance (eigen value $>1.56$ ).

\section{Mental toughness}

In this study, we used the 18-item short form of the MTQ48, ${ }^{33}$ which measures total MT. Previous studies have reported high correlations between the short and long forms of MTQ. ${ }^{33}$ Evidence has also been provided for the factorial validity of MTQ48 in previous studies. ${ }^{31,55}$ MTQ instruments generally 
have high test-retest reliability as well as high internal consistency and are moderately associated with other psychological constructs such as optimism and self-efficacy. ${ }^{31,33,56,57}$ Sample items are "I generally cope well with any problems that occur" or "However bad things are, I usually feel they will work out positively in the end". Items on the MTQ18 were anchored on a 5-point Likert scale from 1 (= strongly disagree) to 5 (= strongly agree), with higher scores reflecting greater MT. Responses across items were summed to obtain an overall MT index (Cronbach's $\alpha=0.84$ ).

\section{Physical activity}

To obtain information on PA, the short version of the International Physical Activity Questionnaire (IPAQ) was used. This questionnaire was developed by a working group initiated by the World Health Organization and the Centers for Disease Control and Prevention. Results from 12 countries demonstrate that the IPAQ has comparable reliability and validity to other self-reported measures of PA. ${ }^{58}$ The short (self-administered, seven-item), last-week version of the IPAQ was administered, asking about the time spent being physically active over the last 7 days. Minutes of sitting, walking, as well as moderate-intensity (walking not included) and vigorous-intensity activities were computed for the past week. The IPAQ questionnaires (short and long versions), including definitions of moderate and vigorous activity, are available at www.ipaq.ki.se.

\section{Statistical analyses}

\section{Preliminary computations}

The age range was 19 years; therefore, we performed a series of correlational correlations between age and the DT, MT, and PA. Correlation coefficients ranged from 0.02 to 0.09 , $P>0.21$. Therefore, age was not introduced as confounder.

First, a series of Pearson's correlations was computed to calculate the associations between DT traits, MT, and PA. Next, a series of Student's $t$-tests was performed to calculate differences in DT traits, MT, and PA in both sexes. The level of significance was set at $\alpha \leq 0.05$, though we also computed effect sizes (Cohen's $d$ ), with $d<0.49$ indicating small effect sizes (S), $0.50<d<0.79$ indicating medium effect sizes (M), and $d \geq 0.80$ indicating large effect sizes (L). Statistical analyses were performed with SPSS ${ }^{\circledR} 20.0$ (IBM Corporation, Armonk NY, USA) for Apple Mac ${ }^{\circledR}$.

\section{Results \\ Associations between DT traits, MT, and PA}

All descriptive and correlational statistics of DT traits, MT, and PA are reported in Table 1. Machiavellianism, narcissism, psychopathy, and overall DT traits were all positively and significantly associated with MT.

Further, higher Machiavellianism, narcissism, DT overall score, and MT were associated with higher PA (vigorous) scores, and PA (walking) was positively and significantly associated with psychopathy.

\section{Differences for scores of DT traits, MT, and PA between the sexes}

Table 2 reports all descriptive and inferential statistics for DT traits, MT, and PA, comparing men and women participants.

Relative to men, women reported lower scores for psychopathy and overall DT. No significant mean differences were found for Machiavellianism, narcissism, MT, or PA (vigorous and moderate PA, and walking).

\section{Discussion}

The key findings of the present study were that overall DT and specific DT traits were associated with MT and PA in a sample of young Iranian adults. The present results add to the current knowledge in an important way in that we were able to show an association between DT traits, MT, and PA among participants in a non-Western country.

Three hypotheses were formulated, and each of these is considered in turn.

Table I Inter-correlations and descriptive statistics of study variables

\begin{tabular}{|c|c|c|c|c|c|c|c|c|}
\hline & $\mathbf{M}$ & $\mathbf{N}$ & $\mathbf{P}$ & MT & Vigorous PA & Moderate PA & Walking & $\begin{array}{l}\text { Descriptive statistics, } \\
\text { mean (SD) }\end{array}$ \\
\hline Machiavellianism & - & $0.29 *$ & $0.22 *$ & $0.45^{*}$ & $0.117 * *$ & 0.045 & -0.024 & $63.4 I(7.26)$ \\
\hline Narcissism & & - & $0.34 *$ & $0.50 *$ & $0.113^{* *}$ & 0.016 & 0.047 & 127.49 (20.75) \\
\hline Psychopathy & & & - & $0.20 *$ & 0.088 & 0.076 & $0.153 * *$ & 102.85 (15.02) \\
\hline DT Composite Score & & & & $0.53 *$ & $0.146^{*}$ & 0.064 & 0.081 & $-0.001(0.71)$ \\
\hline Mental Toughness & & & & - & $0.192 *$ & -0.012 & 0.089 & $62.39(7.68)$ \\
\hline Descriptive statistics, & & & & & 435.35 (192.15) & $578.24(266.69)$ & 497.94 (209.58) & \\
\hline mean $(\mathrm{SD})$ & & & & & (min/week) & (min/week) & (min/week) & \\
\hline
\end{tabular}

Notes: *Correlation is significant at the 0.01 level (two-tailed). **Correlation is significant at the 0.05 level (two-tailed).

Abbreviations: M, Machiavellianism; N, narcissism; P, psychopathy; min, minutes; MT, mental toughness; PA, physical activity; DT, Dark Triad; SD, standard deviation. 
Table 2 Mental toughness, Dark Triad scores, and physical activity categories, separately by sexes

\begin{tabular}{|c|c|c|c|c|}
\hline & \multicolumn{2}{|l|}{ Mean \pm SD } & \multirow[t]{2}{*}{$t$} & \multirow[t]{2}{*}{ d } \\
\hline & Men $(n=165)$ & Women $(n=176)$ & & \\
\hline Machiavellianism & $63.97 \pm 7.66$ & $62.84 \pm 6.85$ & -1.437 & -0.156 \\
\hline Narcissism & $129.23 \pm 19.98$ & $|25.74 \pm 2| .5 \mid$ & -1.553 & -0.168 \\
\hline Psychopathy & $105.86 \pm 15.07$ & $99.83 \pm 14.96$ & $-3.702 *$ & -0.402 \\
\hline DT composite (z-transformed) & $0.12 \pm 0.68$ & $-0.11 \pm 0.74$ & $-3.098^{*}$ & -0.336 \\
\hline Mental toughness & $62.55 \pm 7.79$ & $62.23 \pm 7.57$ & -0.390 & -0.042 \\
\hline Physical activity (vigorous) & $461.55 \pm 256.40$ & $409.130 \pm 127.89$ & -0.464 & -0.051 \\
\hline Physical activity (moderate) & $586.50 \pm 287.20$ & $569.98 \pm 246.18$ & -0.129 & -0.014 \\
\hline Physical activity (walking) & $539.53 \pm 281.46$ & $456.35 \pm 137.71$ & -0.417 & -0.046 \\
\hline
\end{tabular}

Notes: Total vigorous/moderate/walking PA per week $=($ sum of minutes per day $) \times($ days per week $) . d$ is Cohen's $d . * P<0.05$.

Abbreviations: SD, standard deviation; PA, physical activity; DT, Dark Triad.

Our first hypothesis was that there would be an association between DT and MT, and this was confirmed. Thus, we were able to replicate the findings reported by Onley et al. ${ }^{27}$ However, in contrast to their ${ }^{27}$ findings, we were also able to show that MT was consistently and positively associated with all facets of DT. Given that the data available to us cannot clarify why we found robust associations between DT and MT, when Onley et al's finding ${ }^{27}$ did not, we offer the following suggestion: By definition, mentally tough individuals feel committed to their aims and goals (commitment), ${ }^{33}$ while feeling committed to own goals is also characteristic of those scoring high on Machiavellianism: 5. Indeed, Machiavellianism is closely related to self-interest, personal gain, and achievement of own aims. ${ }^{1,5,9}$ In this view, toughness might be considered one of the proximal, downstream factors that enable those high on the DT to be successful in pursuing their goals that are often offensive to people. Accordingly, we may assume that mentally tough individuals trying to achieve their aims could disregard others' needs as those scoring high on psychopathy tend to do. Mentally tough individuals report having high confidence in their abilities; likewise, those with higher narcissism scores have confidence in their abilities (though others may not share their opinion of themselves). A further explanation might be that items in the two questionnaires have common variance. Future studies might investigate these issues at a statistical level.

Our second hypothesis was that both DT and MT would be associated with PA, and the pattern of results confirmed this. Therefore, we hold that the present results add to the current literature in an important way: DT and vigorous, but not moderate, PA are associated. We also note that both in the present study and in previous studies ${ }^{30,46}$ only vigorous PA appears to be robustly associated with psychological traits such as DT and MT. From the present study, we do not have any direct evidence as to why vigorous but not moderate PA should be associated with DT, and previous explanations for this remain somewhat unsatisfactory. ${ }^{30,46}$ The following may be a more plausible explanation: Vigorous exercising demands planning, organization, engagement, renouncing easier and more reward-oriented activities, as well as resistance to pain, time pressures, and, for example, health concerns. Accordingly, we might expect that strongly goal-oriented and self-confident ${ }^{59}$ individuals are physically vigorously active. Another possibility is that both MT traits and DT traits are acquired in the course of long-term, regular, and vigorous training in sports with possibly a more competitive character. Accordingly, MT and DT traits may have emerged over time among those participants in the present study who practiced more exercise in childhood and adolescence. In this regard, Brand et $\mathrm{al}^{46}$ showed that a relation was already apparent between MT and vigorous, but not low to moderate, PA in preadolescents and adolescents.

Our third hypothesis was that women would have lower DT, MT, and PA scores than men; this was partially confirmed because higher DT traits scores were observed in men compared to women participants, while no differences were observed as regards subjective PA. Higher DT scores were expected in men compared to women participants, and the reason might be the higher intrasexual competition, as also the fact that economically more successful men attain higher in social dominance, which, again, has a favorable impact on short-term mating. Accordingly, the present pattern of results only partially mirrors the findings reported by Gerber et $\mathrm{al}^{30,32}$ and others. ${ }^{21,47,49,54}$

Despite the intriguing findings, several limitations warn against overgeneralization. First, we relied entirely on selfratings. Experts' rating and objective data would enhance the validity of the present pattern of results. This holds particularly true for two main aspects: PA and personality traits on Axis II of the Diagnostic and Statistical Manual of Mental Disorders Fifth Edition (DSM-5) ${ }^{60}$ As regards PA, future studies might assess it via activity trackers, 
for example, of the kind available on smart phones, or using commercially available actigraphs. As regards personality traits on the Axis II of the DSM-5, ${ }^{60}$ again, experts' ratings would shed more light on the participants' possible personality of psychopathology. This is critical, as data were gathered via an online survey, which by definition precludes both direct contact with the participants and expert assessment. In this view, as with any kind of online research, data might be biased. And accordingly, second, only participants willing and able to complete the online survey took part in the study and accordingly a systematic sample bias cannot be entirely ruled out. In this regard, third, the present pattern of results might have emerged as a result of further latent and unassessed factors, which might have biased two or more dimensions in the same direction. This comment holds particularly true as regards sleep-altering psychological processes such as stress, social interaction, anxiety, and impulsivity. Fourth, Figueredo et $\mathrm{al}^{61}$ proposed a multisample structural equation model to gain further insight into the latent factors of the DT, whereas we focused on a more basic statistical approach.

\section{Conclusion}

Among a sample of young adults, higher scores on DT traits were associated with greater MT and higher vigorous PT. Further, apart from overall DT score and psychopathy, no differences were observed between the sexes.

\section{Acknowledgment}

The authors wish to thank Nick Emler, University of Surrey, Surrey, UK, for proofreading the manuscript.

\section{Disclosure}

The authors report no conflicts of interest in this work.

\section{References}

1. Paulhus DL, Williams KM. The dark triad of personality: narcissism, Machiavellianism, and psychopathy. J Res Pers. 2002;36(6): 556-563.

2. Veselka L, Vernon PA. Introduction to the special issue on the dark triad and related traits. Pers Individ Dif. 2014;67:1.

3. Jakobwitz S, Egan V. The dark triad and normal personality traits. Pers Individ Dif. 2006;40(2):331-339.

4. Cherulnik PD, Way JH, Ames S, Hutto DB. Impressions of high and low Machiavellian men. J Pers. 1981;49(4):388-400.

5. Knecht $\mathrm{T}$. [What is Machiavellian intelligence? Views on a little appreciated side of the psyche]. Nervenarzt. 2004;75(1):1-5. German.

6. Campbell WK, Reeder GD, Sedikides C, Elliot AJ. Narcissism and comparative self-enhancement strategies. J Res Pers. 2000;34(3): 329-347.

7. Vernon PA, Villani VC, Vickers LC, Harris JA. A behavioral genetic investigation of the dark triad and the big 5. Pers Individ Dif. 2008; 44(2):445-452.
8. Del Gaizo AL, Falkenbach DM. Primary and secondary psychopathictraits and their relationship to perception and experience of emotion. Pers Individ Dif. 2008;45(3):206-212.

9. Furnham A, Richards SC, Paulhus DL. The dark triad of personality: a 10 year review. Soc Personal Psychol Compass. 2013;7(3): 199-216.

10. Furnham A, Richards S, Rangel L, et al. Measuring malevolence: quantitative issues surrounding the dark triad of personality. Pers Individ Dif. 2014;67:114-121.

11. McHoskey JW, Worzel W, Szyarto C. Machiavellianism and psychopathy. J Pers Soc Psychol. 1998;74(1):192.

12. Book A, Visser BA, Volk AA. Unpacking "evil": claiming the core of the dark triad. Pers Individ Dif. 2015;73:29-38.

13. Küfner ACP, Dufner M, Back M. Das Dreckige Dutzend und die Niederträchtigen Neun-Zwei Kurzskalen zur Erfassung von Narzissmus, Machiavellismus, und Psychopathie [The Dirty Dozen and the Naughty Nine - Short scales for the assessment of narcissism, Machiavellianism and psychopathy]. Diagnostica. 2014;1:1-16. German.

14. Miller JD, Dir A, Gentile B, Wilson L, Pryor LR, Campbell WK. Searching for a vulnerable dark triad: comparing factor 2 psychopathy, vulnerable narcissism, and borderline personality disorder. $J$ Pers. 2010;78(5):1529-1564.

15. Baughman HM, Jonason PK, Veselka L, Vernon PA. Four shades of sexual fantasies linked to the dark triad. Pers Individ Dif. 2014;67: $47-51$.

16. Smith CV, Hadden BW, Webster GD, Jonasond PK, Gesselmanc AN, Cryselc LC. Mutually attracted or repulsed? Actor-partner interdependence models of dark triad traits and relationship outcomes. Pers Individ Dif. 2014;67:35-41.

17. Jones DN, Paulhus DL. Introducing the short dark triad (SD3) a brief measure of dark personality traits. Assessment. 2014;21(1):28-41.

18. Porter S, Bhanwer A, Woodworth M, Black PJ. Soldiers of misfortune: an examination of the dark triad and the experience of schadenfreude. Pers Individ Dif. 2014;67:64-68.

19. Black PJ, Woodworth M, Porter S. The big bad wolf? The relation between the dark triad and the interpersonal assessment of vulnerability. Pers Individ Dif. 2014;67:52-56.

20. Goncalves MK, Campbell L. The dark triad and the derogation of mating competitors. Pers Individ Dif. 2014;67:42-46.

21. Jonason PK, Tost J. I just cannot control myself: the dark triad and self-control. Pers Individ Dif. 2010;49(6):611-615.

22. Muris $P$, Meesters C, Timmermans A. Some youths have a gloomy side: correlates of the dark triad personality traits in non-clinical adolescents. Child Psychiatry Hum Dev. 2013;44(5):658-665.

23. Jonason PK, Jones A, Lyons M. Creatures of the night: chronotypes and the dark triad traits. Pers Individ Dif. 2013;55(5):538-541.

24. Aghababaei N, Mohammadtabar S, Saffarinia M. Dirty dozen vs the H factor: comparison of the dark triad and honesty-humility in prosociality, religiosity, and happiness. Pers Individ Dif. 2014;67:6-10.

25. Fox J, Rooney MC. The dark triad and trait self-objectification as predictors of men's use and self-presentation behaviors on social networking sites. Pers Individ Dif. 2015;76:161-165.

26. Carter GL, Campbell AC, Muncer S. The dark triad personality: attractiveness to women. Pers Individ Dif. 2014;56:57-61.

27. Onley M, Veselka L, Schermer JA, Vernon PA. Survival of the scheming: a genetically informed link between the dark triad and mental toughness. Twin Res Hum Genet. 2013;16(06):1087-1095.

28. Gucciardi D, Gordon S. Mental Toughness in Sport: Developments in Theory and Research. London: Routledge; 2011.

29. Crust L, Azadi K. Mental toughness and athletes' use of psychological strategies. Eur J Sport Sci. 2010;10(1):43-51.

30. Gerber M, Kalak N, Lemola S, et al. Adolescents' exercise and physical activity are associated with mental toughness. Ment Health Phys Act. 2012;5(1):35-42.

31. Gerber M, Kalak N, Lemola S, et al. Are adolescents with high mental toughness levels more resilient against stress? Stress Health. 2013;29(2):164-171. 
32. Gerber M, Brand S, Feldmeth AK, et al. Adolescents with high mental toughness adapt better to perceived stress: a longitudinal study with Swiss vocational students. Pers Individ Dif. 2013;54(7):808-814.

33. Clough P, Earle K, Sewell D. Mental toughness: the concept and its measurement. In: Cockerill I, editor. Solutions in Sport Psychology. London: Thomson; 2002:32-43.

34. Brand S, Gerber M, Kalak N, et al. "Sleep well, our tough heroes!" in adolescence, greater mental toughness is related to better sleep schedules. Behav Sleep Med. 2014;12(6):444-454.

35. Brand S, Gerber M, Kalak N, et al. Adolescents with greater mental toughness show higher sleep efficiency, more deep sleep and fewer awakenings after sleep onset. J Adolesc Health. 2014;54(1):109-113.

36. Crust L. Mental toughness in sport: a review. Int J Sport Exerc Psychol. 2007;5(3):270-290.

37. Crust L. A review and conceptual re-examination of mental toughness: implications for future researchers. Pers Individ Dif. 2008; 45(7):576-583.

38. Gerber M. [Mental toughness in sport]. Sportwissenschaft. 2011; 41(4):283-299. German.

39. Connaughton D, Hanton S, Jones G. A framework of mental toughness in the world's best performers. Sport Psychol. 2007;21(2):243-264.

40. Andersen MB. Who's Mental, Who's Tough and Who's Both? In: Gucciardi DF, Gordon S, editors. Mental toughness in sport: developments in research and theory. Routledge Research in Sport and Exercise Science. Routledge, Abington, Oxon, UK; New York; 2011:69-88.

41. Coulter TJ, Mallett CJ, Gucciardi DF. Understanding mental toughness in Australian soccer: perceptions of players, parents, and coaches. J Sports Sci. 2010;28(7):699-716.

42. Levy AR, Polman RC, Clough PJ, Marchant DC, Earle K. Mental toughness as a determinant of beliefs, pain, and adherence in sport injury rehabilitation. $J$ Sport Rehabil. 2006;15(3):246-254.

43. Tibbert SJ. Mental Toughness and Overtraining Behaviours. Melbourne, VIC: Victoria University; 2013.

44. Richardson SO, Andersen MB, Morris T. Overtraining Athletes. Personal Journeys in Sport. Champaign, IL: Human Kinetics; 2008.

45. Gucciardi D, Mallett C. Understanding mental toughness and its development in sport. In: Hanrahan SJ, Andersen MB, editors. Routledge Handbook of Applied Sport Psychology. London: Routledge; 2010: 547-556.

46. Brand S, Kalak N, Gerber M, et al. During early and mid-adolescence, greater mental toughness is related to increased sleep quality and quality of life. J Health Psychol. Epub 2014 Jul 24.
47. Jonason PK, Kavanagh P. The dark side of love: love styles and the dark triad. Pers Individ Dif. 2010;49(6):606-610.

48. Jonason PK, Li NP, Buss DM. The costs and benefits of the dark triad: implications for mate poaching and mate retention tactics. Pers Individ Dif. 2010;48(4):373-378.

49. Jonason PK, Webster GD. The dirty dozen: a concise measure of the dark triad. Psychol Assess. 2010;22(2):420.

50. Brand S, Beck J, Kalak N, et al. Dream recall and its relationship to sleep, perceived stress, and creativity among adolescents. J Adolesc Health. 2011;49(5):525-531.

51. Christie R, Geis FL. Studies in Machiavellianism. Waltham, MA Academic Press; 2013.

52. Raskin R, Terry H. A principal-components analysis of the narcissistic personality inventory and further evidence of its construct validity. J Pers Soc Psychol. 1988;54(5):890.

53. Hare RD, Hart SD, Harpur TJ. Psychopathy and the DSM-IV criteria for antisocial personality disorder. J Abnorm Psychol. 1991;100(3):391.

54. Jonason PK, Li NP, Webster GD, Schmitt DP. The dark triad: facilitating a short-term mating strategy in men. Eur J Pers. 2009;23(1):5-18.

55. Perry JL, Clough PJ, Crust L, Earle K, Nicholls AR. Factorial validity of the mental toughness questionnaire-48. Pers Individ Dif. 2013; 54(5):587-592.

56. Horsburgh VA, Schermer JA, Veselka L, Vernon PA. A behavioural genetic study of mental toughness and personality. Pers Individ Dif. 2009;46(2):100-105.

57. Kaiseler M, Polman R, Nicholls A. Mental toughness, stress, stress appraisal, coping and coping effectiveness in sport. Pers Individ Dif. 2009; 47(7):728-733.

58. Booth ML, Ainsworth BE, Pratt M, et al. International physical activity questionnaire: 12-country reliability and validity. Med Sci Sports Exerc. 2003;35(8):1381-1395.

59. Liu SH, Waring ME, Eaton CB, Lapane KL. Association of objectively measured physical activity and metabolic syndrome among US adults with osteoarthritis. Arthritis Care Res (Hoboken). 2015;67(10): 1371-1378.

60. American Psychiatric Association. Diagnostic and Statistical Manual of Mental Disorders 5th edition: DSM 5. Washington DC: American Psychiatric Association; 2013.

61. Figueredo AJ, Gladden PR, Sisco MM, Patch EA, Jones DN. The unholy trinity: the dark triad, coercion, and Brunswik-symmetry. Evol Psychol. 2015;13(2):435-454
Neuropsychiatric Disease and Treatment

\section{Publish your work in this journal}

Neuropsychiatric Disease and Treatment is an international, peerreviewed journal of clinical therapeutics and pharmacology focusing on concise rapid reporting of clinical or pre-clinical studies on a range of neuropsychiatric and neurological disorders. This journa is indexed on PubMed Central, the 'PsycINFO' database and CAS,

\section{Dovepress}

and is the official journal of The International Neuropsychiatric Association (INA). The manuscript management system is completely online and includes a very quick and fair peer-review system, which is all easy to use. Visit http://www.dovepress.com/testimonials.php to read real quotes from published authors. 